Kansas State University Libraries

New Prairie Press

\title{
ANALYSIS OF GENOTYPE-BY-ENVIRONMENT INTERACTION WITH AMMI MODELS USING SAS PROC MIXED
}

Raul E. Macchiavelli

James S. Beaver

Follow this and additional works at: https://newprairiepress.org/agstatconference

Part of the Agriculture Commons, and the Applied Statistics Commons

\section{c) (1) () $\Theta$}

This work is licensed under a Creative Commons Attribution-Noncommercial-No Derivative Works 4.0 License.

\section{Recommended Citation}

Macchiavelli, Raul E. and Beaver, James S. (1999). "ANALYSIS OF GENOTYPE-BY-ENVIRONMENT INTERACTION WITH AMMI MODELS USING SAS PROC MIXED," Conference on Applied Statistics in Agriculture. https://doi.org/10.4148/2475-7772.1268

This is brought to you for free and open access by the Conferences at New Prairie Press. It has been accepted for inclusion in Conference on Applied Statistics in Agriculture by an authorized administrator of New Prairie Press. For more information, please contact cads@k-state.edu. 


\title{
ANALYSIS OF GENOTYPE-BY-ENVIRONMENT INTERACTION WITH AMMI MODELS USING SAS PROC MIXED
}

Raúl E. Macchiavelli and James S.Beaver

Dept. of Agronomy and Soils, Univ. of Puerto Rico, P.O. Box 9030, Mayagüez, PR 00681-9030

\begin{abstract}
Genotype-by-environment (GE) interaction can be analyzed using different approaches. Among these, the additive main effects and multiplicative interaction model yields useful interpretations and can be applied successfully to plant breeding programs. In this paper we review fitting strategies for this model and show how to combine the capabilities of the Mixed and IML procedures in SAS to fit this model. This permits straightforward use of likelihood-based inference in standard and non standard situations like complex experimental designs. The proposed procedures were applied to data from red mottled bean variety trials conducted in the Dominican Republic and Puerto Rico in 9 environments with 30 lines (15 with indeterminate and 15 with determinate growth habit).
\end{abstract}

\section{INTRODUCTION}

Yield trials are usually repeated in different environments (typically a combination of locations and years). This permits general conclusions to be drawn, but also makes the interpretation of the interaction between genotype and environment (GE) interaction more difficult. Understanding this interaction is one of the aspects on which a successful plant breeding program depends (Gauch, 1988).

There are different approaches used to model GE interaction, among them the concurrence model, the regression on the mean models and the additive main effects and multiplicative interaction (AMMI) models (van Eeuwijk and Kroonenberg, 1998). Because it is

the most versatile approach, the AMMI model has been used in a variety of situations (see for example Shafii et al., 1992, and Aguiluz, 1998).

In this paper we review this model and show how to fit it using the Mixed and IML procedures in SAS. We apply the proposed methodology to red mottled bean (Phaseolus vulgaris L.) variety trials conducted in the Dominican Republic and Puerto Rico. In the Dominican Republic and Haiti, red mottled beans are grown by small-scale farmers both on hillsides and in valleys using diverse cultural practices. Hence, it is desirable to develop red mottled varieties which perform predictably over a wide range of environmental conditions. In this study 30 different lines were analyzed: 15 with indeterminate and 15 with determinate growth habit under 9 different environments (Beaver et al., 1996). 


\section{METHODOLOGY}

The general model used for a typical variety trial is:

$$
Y_{i j k}=\mu+\alpha_{i}+\delta_{k(i)}+\beta_{j}+\alpha \beta_{i j}+\varepsilon_{i j k}
$$

where $\mu, \alpha_{i}, \beta_{j}$, and $\alpha \beta_{i j}(i=1, \ldots, e ; j=1, \ldots, g)$ are, respectively, the (fixed) general mean and the (fixed) effects of the environment, the genotype and the GE interaction. The term $\delta_{k(i)}$ is the (random) effect of the $k$ th. block $(k=1, \ldots, n)$ in the $i$ th. environment, $\delta$ i.i.d. $N\left(0, \sigma^{2}\right.$ block $)$, and the term $\varepsilon_{i j k}$ is the (random) error term, $\varepsilon_{i j k}$ i.i.d. $N\left(0, \sigma^{2}\right)$.

The AMMI model expresses each interaction term as a sum of multiplicative terms:

$$
\alpha \beta_{i j}=\sum_{t=1}^{m} \lambda_{t} a_{t i} b_{t j}+\beta_{i j}
$$

where $\lambda_{t},\left\{a_{t l}, \ldots, a_{t e}\right\},\left\{b_{t l}, \ldots, b_{t e}\right\}$, are, respectively, the $t$ th singular value, the $t$ th column of the left-side matrix and the $t$ th row of the right-side matrix of the singular value decomposition of $\boldsymbol{E}$, the $e \times g$ matrix of interaction effects (i.e., the $i j$ th. element of $\boldsymbol{E}$ is $\alpha \beta_{i j}$ ) (Mandel, 1971; Rao, 1973). The singular value decomposition has the property that the sum of squares of the interaction, $S S G E$, equals $\Sigma_{t} \lambda_{t}^{2}$, and therefore the values $\lambda_{t}^{2}$ can be interpreted as the portion of the interaction sum of squares associated with the particular multiplicative component.

The estimation of the $\lambda \mathrm{s}, a \mathrm{~s}$ and $b \mathrm{~s}$ is done according to the procedure discussed by Mandel (1971). It consists in obtaining the residuals after fitting a main-effects-only model, and computing the singular value decomposition of the estimated interaction effects. Price and Shafii (1993) present a SAS IML program to do this. Note that for balanced data it is equivalent to compute the residuals from averages or from using all replicates and averaging the resulting residuals. It is not clear at present which of the two alternatives is preferable when the data are unbalanced.

For parsimony, $m$ (the number of singular values retained in eq. 2) should be small, preferably much smaller than its maximum, $\min (e, g)$. Likelihood ratio tests have been proposed to determine the number of multiplicative terms to retain in (2) (Hegeman and Johnson, 1976; Milliken and Johnson, 1989). These tests can be computed directly using SAS Proc Mixed (SAS Institute, 1997) by fitting apropriate models under the null and alternative hypotheses, and letting the program compute the corresponding maximized likelihoods.

The hypotheses for testing whether it suffices to retain up to the $m$ th multiplicative term are:

$$
\begin{gathered}
H_{0}: E\left(Y_{i j k}\right)=\mu+\alpha_{i}+\beta_{j}+\sum_{t}^{m} \lambda_{t} a_{t i} b_{t j} \\
H_{a}: E\left(Y_{i j k}\right)=\mu+\alpha_{i}+\beta_{j}+\alpha \beta_{i j}
\end{gathered}
$$


Under the alternative hypothesis, the maximized likelihood is computed automatically by SAS Proc Mixed. In order to compute the maximized likelihood under $H_{0}$, one can compute the residuals after fitting all fixed effects in the model:

$$
r_{i j k}=Y_{i j k}-\left(\hat{\mu}+\hat{\alpha}_{i}+\hat{\beta}_{j}+\sum_{t=1}^{m} \hat{\lambda}_{t} \hat{a}_{t i} \hat{b}_{t j}\right) .
$$

Once these residuals are computed, they can be used as the dependent variable in a model with no fixed effects, no intercept, and the same random effects present in the original model (in the example, $\delta_{k(i)}$ and $\varepsilon_{i j k}$. If the data set is balanced, then the estimation procedure described above yields also the maximum likelihood estimators of the fixed effects, and hence the maximized likelihood can be obtained directly from the residuals $r_{i j k}$. To verify this, note that an individual term in the maximized log likelihood under the null hypothesis is:

$$
\text { conatant }-\frac{1}{2} \log \left(\widehat{\operatorname{Var}}\left(Y_{i j k}\right)\right)-\frac{1}{2} \frac{\left(Y_{i j k}-\tilde{\mu}_{i j k}\right)^{2}}{\widehat{\operatorname{Var}}\left(Y_{i j k}\right)}
$$

The numerator of the last term of this equation is $r_{i j k}{ }^{2}$, and therefore the maximized likelihood can be computed directly for the proposed model using the residuals.

Once both maximized likelihoods are available, a likelihood ratio test statistic can be computed by taking the difference $-2 \log L_{H O}-\left(-2 \log L_{H a}\right)$. Since the null hypothesis is a proper subset of the alternative, this statistic has an asymptotic chi-square asymptotic null distribution. The degrees of freedom can be aproximated using the formula suggested by Gollob (1968):

$$
d f=(e-1)(g-1)-\Sigma(g+e-1-2 t)=(e-1)(g-1)-m(e+g-m-2) .
$$

Other approximations could be used (Mandel, 1971; Milliken and Johnson, 1989).

In summary, the following steps are necessary to fit the AMMI models in SAS:

1. Read data and fit a model with main effects but no interaction.

2. Obtain residuals and average them to obtain the $\boldsymbol{E}$ matrix (estimated GE interaction terms).

3. Obtain the singular value decomposition of $\boldsymbol{E}$ and generate data sets with the results (Shafii and Price, 1998).

4. Generate data sets containing the fitted values and residuals for models containing main effects and 1,2,3, etc. multiplicative interaction terms.

5. Fit models using the residuals obtained in 4 as dependent variables, no fixed effects, no intercept and the same random effects used in the model fitted in part 1. Compute the maximized likelihood for each of these models.

6. Fit a general model with main effects and interaction and compute its maximized likelihood.

7. Compute likelihood ratio test statistics for each of the models fitted in 5 and decide how many multiplicative terms to retain. 
8. Compute the AMMI model means and prepare biplots to better interpret the results (Shafii and Price, 1998).

\section{RED MOTTLED BEAN VARIETY TRIALS}

From 1990 to 1992 , several variety trials were carried out to evaluate the performance of breeding lines with determinate and indeterminate growth habit over a wide range of environmental conditions (Beaver et al., 1996). A preliminary ANOVA shows large differences due to environment and genotype, and a large GE interaction $(F=4.14$, p-value $=0.0001)$. Partition of the genotype effects and the GE interaction to account for the different growth habits also show highly significant effects and interaction (see Table 1). It also shows that a mayor contributor to the genotype and GE interaction effects is growth habit. The means show a wide range, from 0.4 to more than 3 ton/ha, with the determinate lines, in general, showing lower yields than the indeterminate ones (see Table 2).

Table 3 shows the percentage of variability associated with each of the singular values. The last 3 columns show the results of the approximte likelihood ratio tests for testing the goodness of fit of a model retaining the first $m$ multiplicative terms $(m=1,2,3,4)$. From this table it is clear that the first three multiplicative terms explain most of the GE interaction, and that additional terms do not improve the fit.

Table 1. ANOVA table for fixed effects in red mottled bean variety trial

\begin{tabular}{|l|r|r|}
\hline Source of Variation & $F$ & p-value \\
\hline Environment & 42.92 & .0001 \\
Growth habit & 134.45 & .0001 \\
Genotype (Growth habit) & 3.40 & .0001 \\
Envir. X Growth habit & 42.65 & .0001 \\
Envir. X Genot. (Growth habit) & 2.76 & .0001 \\
\hline
\end{tabular}

The biplots are presented in Figures 1-4. They were constructed using the program provided by Price and Shafii (1993). Plots involving the first component clearly indicate that the most important aspects of the GE interaction can be explained by the growth habit: essentially all the genotypes with indeterminate growth (numbers 16-30) have positive scores for the first component, while most of the genotypes with determinate growth have negative scores. Because of the multiplicative effects used in the model, a given environment will manifest opposite effects for determinate and indeterminate lines. Environments 6-9 (all of the Puerto Rico planting dates except January 1990) will tend to have a positive correlation with indeterminate lines, while environments 1-5 (Dominican Republic locations and Puerto Rico's January 1990 planting date) seem positively correlated with the lines with determinate growth habit. 
Table 2. Observed mean yields for the red mottled bean variety trials (ton/ha). Lines 1-15 have determinate growth habit and lines 16-30 have indeterminate growth habit. Environments 1-4 are in the Dominican Republic (San Cristóbal Dec. 90, Vallejuelo Sep. 91, Manoguayabo Dec. 91 and San Juan de la Maguana Dec. 91 respectively). Environments 5-9 are in Isabela, Puerto Rico (Jan. 90, Oct. 90, Jan. 91, Oct. 91 and Jan. 92 respectively).

\begin{tabular}{|c|c|c|c|c|c|c|c|c|c|c|}
\hline \multirow[b]{2}{*}{ Line } & \multicolumn{9}{|c|}{ Environment } & \multirow[b]{2}{*}{ Mean } \\
\hline & 1 & 2 & 3 & 4 & 5 & 6 & 7 & 8 & 9 & \\
\hline $1(8738-7 B)$ & 1.13 & 1.23 & 1.81 & 1.56 & 1.11 & 1.16 & 1.44 & 0.38 & 1.38 & 1.24 \\
\hline $2(8738-12 B)$ & 0.88 & 1.52 & 1.68 & 1.23 & 1.26 & 1.18 & 1.74 & 0.35 & 1.55 & 1.27 \\
\hline $3(8738-5 B)$ & 1.10 & 1.40 & 1.34 & 1.29 & 0.97 & 1.24 & 1.77 & 1.47 & 2.30 & 1.43 \\
\hline 4 (Indiana Roja) & 0.72 & 1.10 & 1.35 & 0.75 & 1.26 & 1.07 & 1.60 & 2.26 & 1.54 & 1.30 \\
\hline $5(8738-3 B)$ & 1.29 & 1.94 & 1.75 & 1.21 & 1.13 & 1.61 & 1.68 & 1.03 & 1.92 & 1.51 \\
\hline 6 (Pompadour F) & 0.61 & 1.52 & 1.79 & 1.02 & 1.13 & 1.39 & 1.25 & 0.35 & 1.19 & 1.14 \\
\hline $7(8738-4 B)$ & 1.17 & 1.31 & 1.55 & 1.33 & 1.09 & 1.13 & 1.36 & 1.34 & 1.74 & 1.34 \\
\hline 8 (Pompad. Checa) & 1.00 & 1.06 & 1.80 & 1.27 & 1.09 & 1.32 & 0.98 & 0.74 & 1.08 & 1.15 \\
\hline $9(8738-8 B)$ & 0.83 & 1.60 & 1.93 & 1.10 & 1.12 & 1.85 & 1.13 & 0.56 & 1.43 & 1.28 \\
\hline $10($ Pompadour $\mathrm{N})$ & 1.05 & 1.60 & 1.84 & 1.35 & 1.02 & 0.95 & 1.69 & 0.52 & 1.57 & 1.29 \\
\hline $11(8738-1 B)$ & 1.11 & 1.13 & 1.88 & 1.08 & 1.05 & 0.89 & 1.51 & 1.21 & 1.51 & 1.26 \\
\hline $12(8911-55)$ & 1.03 & 1.31 & 1.21 & 1.25 & 0.90 & 2.41 & 1.25 & 0.28 & 1.08 & 1.19 \\
\hline $13(8857-67)$ & 1.28 & 1.15 & 1.15 & 1.24 & 0.75 & 2.32 & 2.10 & 0.92 & 2.20 & 1.46 \\
\hline $14(\mathrm{PC} 50)$ & 1.25 & 1.58 & 2.53 & 2.08 & 1.09 & 1.88 & 1.05 & 0.47 & 1.38 & 1.48 \\
\hline 15 (Jose Beta) & 1.04 & 1.60 & 1.83 & 1.75 & 1.15 & 1.92 & 1.81 & 0.63 & 1.25 & 1.44 \\
\hline $16(8856-12)$ & 1.42 & 1.40 & 1.06 & 0.76 & 0.93 & 2.92 & 1.84 & 1.99 & 1.55 & 1.54 \\
\hline $17(8856-61)$ & 1.02 & 1.02 & 0.77 & 0.87 & 0.90 & 2.10 & 2.44 & 2.05 & 2.60 & 1.53 \\
\hline $18(8953-12)$ & 0.64 & 0.79 & 0.87 & 0.79 & 1.01 & 2.28 & 1.72 & 2.13 & 2.31 & 1.39 \\
\hline $19(8953-1)$ & 1.03 & 1.25 & 1.13 & 1.15 & 1.17 & 3.08 & 2.19 & 1.54 & 1.81 & 1.59 \\
\hline $20(8953-2)$ & 1.04 & 1.48 & 1.62 & 1.48 & 1.11 & 1.70 & 1.95 & 2.05 & 2.42 & 1.65 \\
\hline $21(8953-3)$ & 0.82 & 1.09 & 1.10 & 1.31 & 0.66 & 2.24 & 1.80 & 2.24 & 2.37 & 1.52 \\
\hline $22(8953-6)$ & 0.78 & 1.15 & 1.01 & 1.46 & 0.84 & 3.15 & 2.20 & 1.65 & 2.11 & 1.59 \\
\hline $23(8953-9)$ & 1.18 & 1.44 & 1.41 & 1.49 & 0.84 & 2.31 & 2.37 & 2.83 & 2.17 & 1.78 \\
\hline $24(8953-10)$ & 1.45 & 1.60 & 1.66 & 1.77 & 1.14 & 1.67 & 2.37 & 1.80 & 2.17 & 1.74 \\
\hline $25(8738-7 B)$ & 1.58 & 0.88 & 1.56 & 1.50 & 0.57 & 1.75 & 2.33 & 1.26 & 2.00 & 1.49 \\
\hline 26 (Pompadour G) & 1.12 & 1.21 & 1.49 & 1.98 & 1.05 & 2.19 & 1.95 & 2.78 & 2.71 & 1.83 \\
\hline 27 (Pompadour V) & 1.29 & 1.16 & 1.26 & 0.92 & 1.19 & 1.70 & 2.30 & 1.93 & 1.82 & 1.51 \\
\hline 28 (Pompadour K) & 1.03 & 1.38 & 1.35 & 1.44 & 1.38 & 2.31 & 1.95 & 1.48 & 1.83 & 1.57 \\
\hline 29 (Pompadour T) & 1.63 & 0.98 & 1.23 & 3.33 & 1.28 & 2.04 & 1.91 & 1.33 & 2.57 & 1.81 \\
\hline $30(8858-28)$ & 1.30 & 1.43 & 1.13 & 1.45 & 1.02 & 3.10 & 2.20 & 2.80 & 2.87 & 1.92 \\
\hline Mean & 1.09 & 1.31 & 1.47 & 1.37 & 1.04 & 1.90 & 1.80 & 1.41 & 1.88 & 1.47 \\
\hline
\end{tabular}


Table 3. Percentage of variability and approximate goodness of fit tests for multiplicative components for red mottled beans variety trials.

\begin{tabular}{|c|r|rr|rrr|}
\hline $\begin{array}{c}\text { Multiplicative } \\
\text { Components }\end{array}$ & \multicolumn{1}{|c|}{$\lambda^{2}$} & \multicolumn{2}{|c|}{ Variance proportion (\%) } & \multicolumn{3}{|c|}{ Goodness of fit tests } \\
\hline 1 & 101.72 & 53.91 & 53.91 & 368.83 & 196 & 0.0000 \\
2 & 34.54 & 18.32 & 72.22 & 237.46 & 162 & 0.0001 \\
3 & 23.97 & 12.71 & 84.93 & 135.48 & 130 & 0.3532 \\
4 & 12.19 & 6.46 & 91.39 & 79.56 & 100 & 0.9345 \\
5 & 6.28 & 3.33 & 94.72 & & & \\
6 & 4.54 & 2.40 & 97.12 & & & \\
7 & 3.15 & 1.67 & 98.79 & & & \\
8 & 2.29 & 1.21 & 100.00 & & & \\
\hline
\end{tabular}

Lines having scores close to 0 for the first 3 components can be interpreted as more stable (presenting more predictable yields in most of the environments). The lines 3, 7, 13, 20, 24, 25 and 28 seem most stable, since their scores for the first component are smaller than 0.1 (in absolute value), and their scores for the second and third components are smaller than 0.3 in absolute value. Furthermore, line 24 combines a high mean yield with predictable performance.

Figure 4 graphs the first component versus the mean yield (ton/ha). From this graph the growth habit effect can be noted: indeterminate lines tend to have higher yields than determinate lines. The genotypes which are closer to the reference line at 0 indicate a greater relative stability. Separate analysis for indeterminate and determinate lines show a similar interaction structure, and 2-3 multiplicative components would need to be retained in each case.

\section{SUMMARY}

In this paper we reviewed the additive main effects and multiplicative interaction model and discussed fitting strategies. We present an algorithm to fit this model and compute goodness of fit ratio tests to decide how many multiplicative components are important. This algorithm combines the capabilities of SAS PROC MIXED and IML. We present an example applying the proposed methodology to data from red mottled bean variety trials conducted in the Dominican Republic and Puerto Rico in 9 environments with 30 lines.

\section{ACKNOWLEDGMENTS}

We thank Mónica Balzarini and a referee for suggestions which greatly improved this paper. 


\section{REFERENCES}

Aguiluz, A. (1998). Evaluacion de híbridos de maíz (Zea mays L.) de grano blanco y amarillo en ambientes de Centroamérica, Panamá y el Caribe en 1996. Agronomía Mesoamericana 9, 28-37.

Beaver, J.S., E. Arnaud-Santana and D.P. Coyne (1996). Yield stability of determinate and indeterminate red mottled beans. Journal of Agriculture of the Univ. of Puerto Rico 80, 187-189.

Gauch, Hugh G, Jr. (1988). Model selection and validation for yield trials with interaction. Biometrics 44, 705-715.

Gollob, H.F. (1968). A statistical model which combines features of factor analytis and analysis of variance. Psychometrika 33, 73-115.

Hegeman, V. and D.E. Johnson (1976). On analyzing two-way AOV data with interaction. Technom. 18, 273-281.

Mandel, J. (1971). A new analysis of variance model for non-additive data. Technom. 13, 1-18.

Milliken, G.A. and D.E. Johnson (1989). Analysis of Messy Data Volume 2: Nonreplicated Experiments. New York: Van Nostrand-Reinhold.

Price, W.J. and B. Shafii (1993). The use of biplots in diagnosing interaction patterns of two-way classification data. Proceedings of the Eighteenth Anual SAS Users Group International Conference, Cary (NC): SAS Institute, Inc.

Rao, C.R. (1973). Linear Statistical Inference and its Applications. 2nd. ed., New York: Wiley.

SAS Institute, Inc. (1997). SAS/STAT Software: Changes and Enhancements through Release 6.12. Cary, NC: SAS Institute, Inc.

Shafii, B., K.A. Mahler, W.J. Price and D.L. Auld (1992). Genotype x environment interaction effects on winter rapeseed yield and oil content. Crop Science 32, 922-927.

Shafii, B. and W.J. Price (1998). Analysis of genotype-by-environment interaction using the additive main effects and multiplicative interaction model and stability estimates. Journal of Agricultural, Biological and Environmental Statistics 3, 335-345.

van Eeuwijk, F.A. and P.M. Kroonenberg (1998). Multiplicative models for interaction in threeway ANOVA, with applications to plant breeding. Biometrics 54, 1315-1333. 
Figure 1. Second vs. First Multiplicative Components. (Large numbers represent environments and small numbers represent genotypes.)

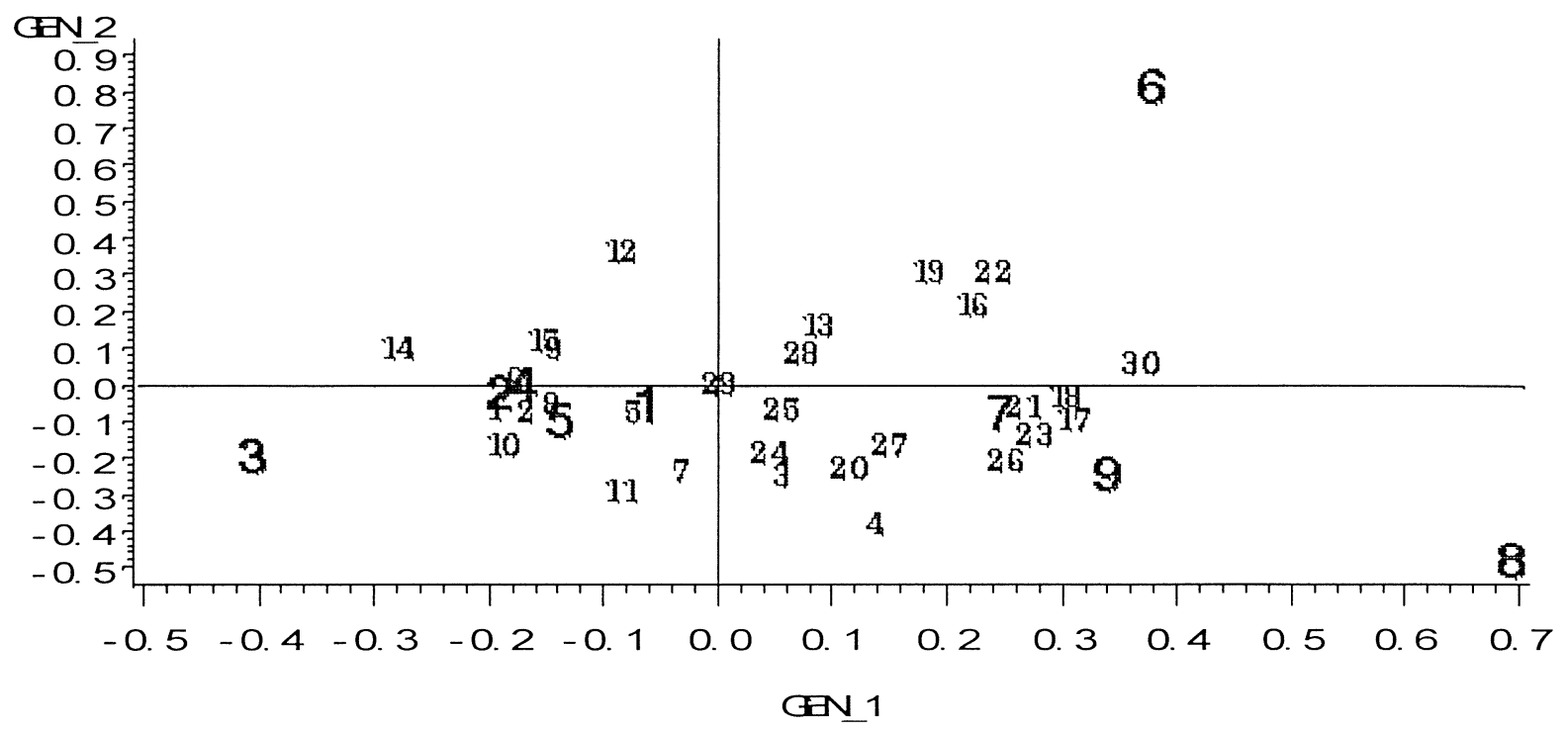

Figure 2. Third vs. First Multiplicative Components. (Large numbers represent environments and small numbers represent genotypes.)

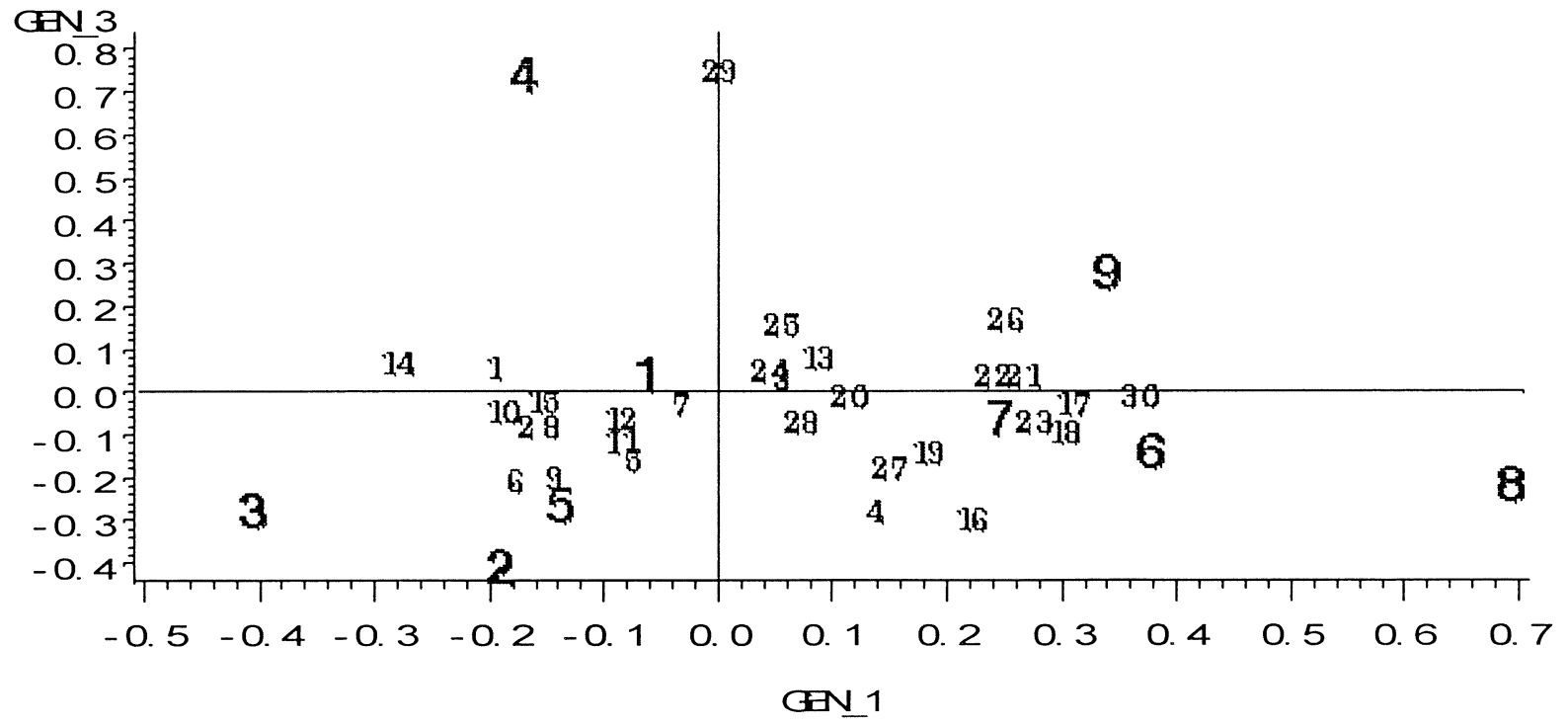


Figure 3. Third vs. Second Multiplicative Components. (Large numbers represent environments and small numbers represent genotypes.)

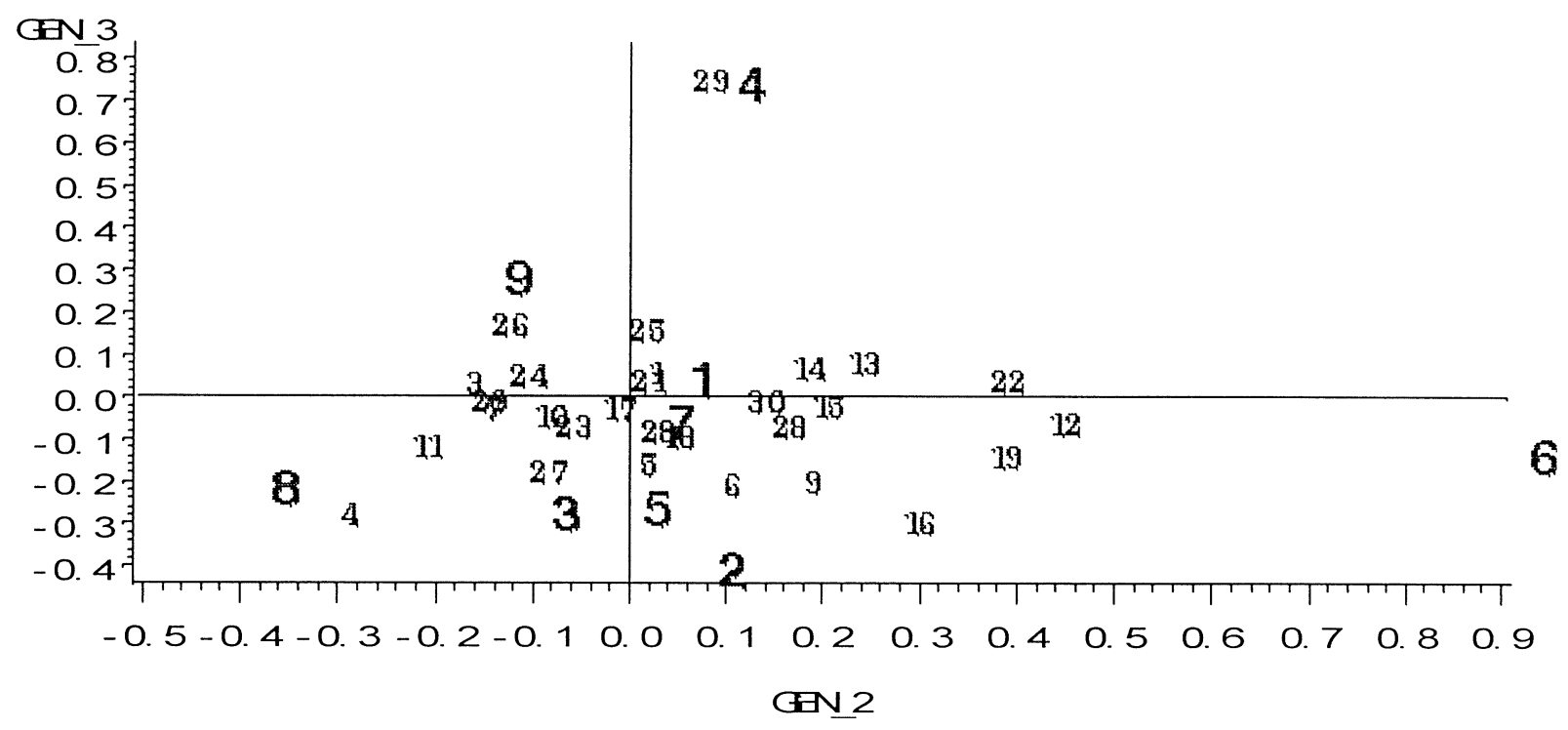

Figure 4. First Multiplicative Component Scores vs. Mean Yields. (Large numbers represent environments and small numbers represent genotypes.)

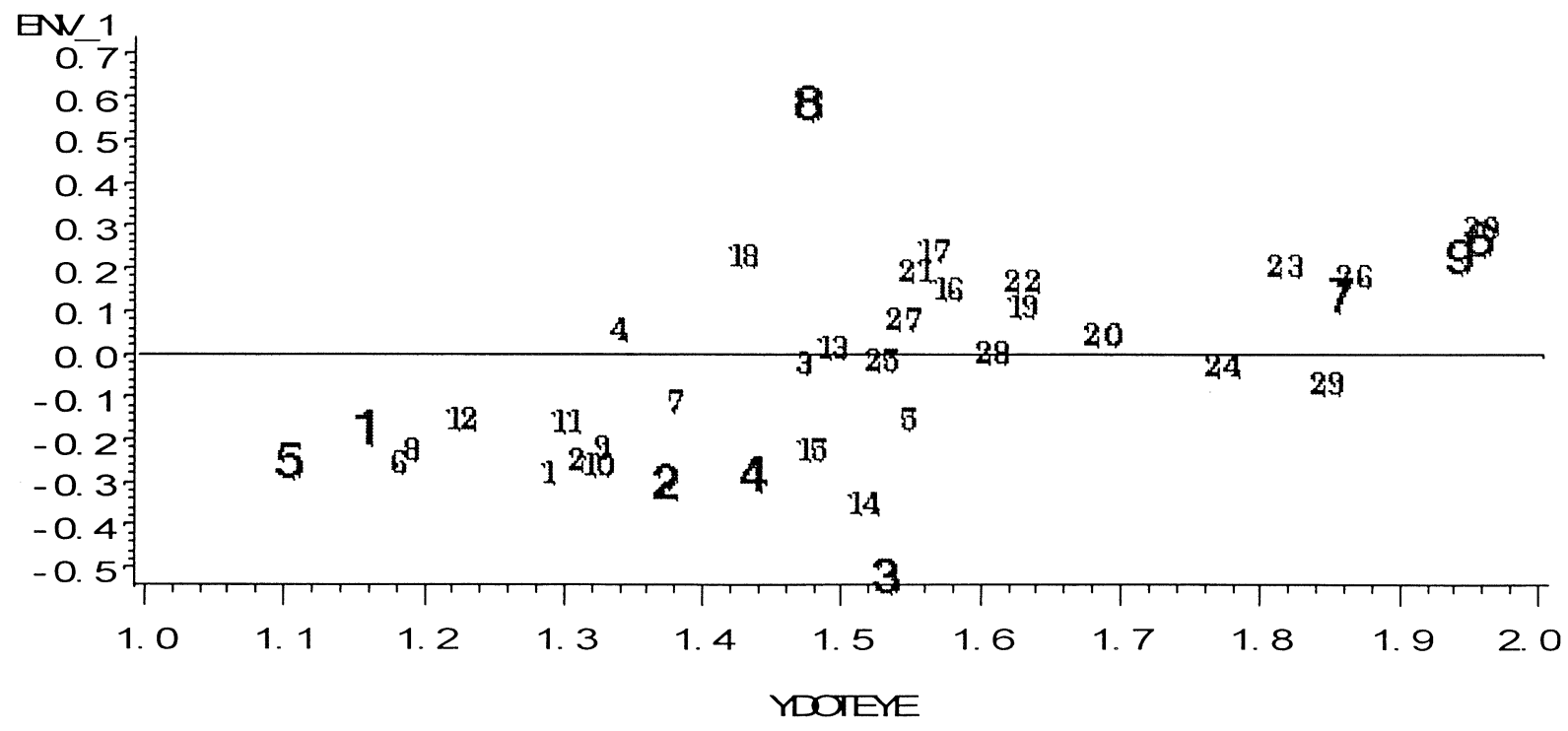




\section{APPENDIX}

\section{SAS program for analyzing the data}

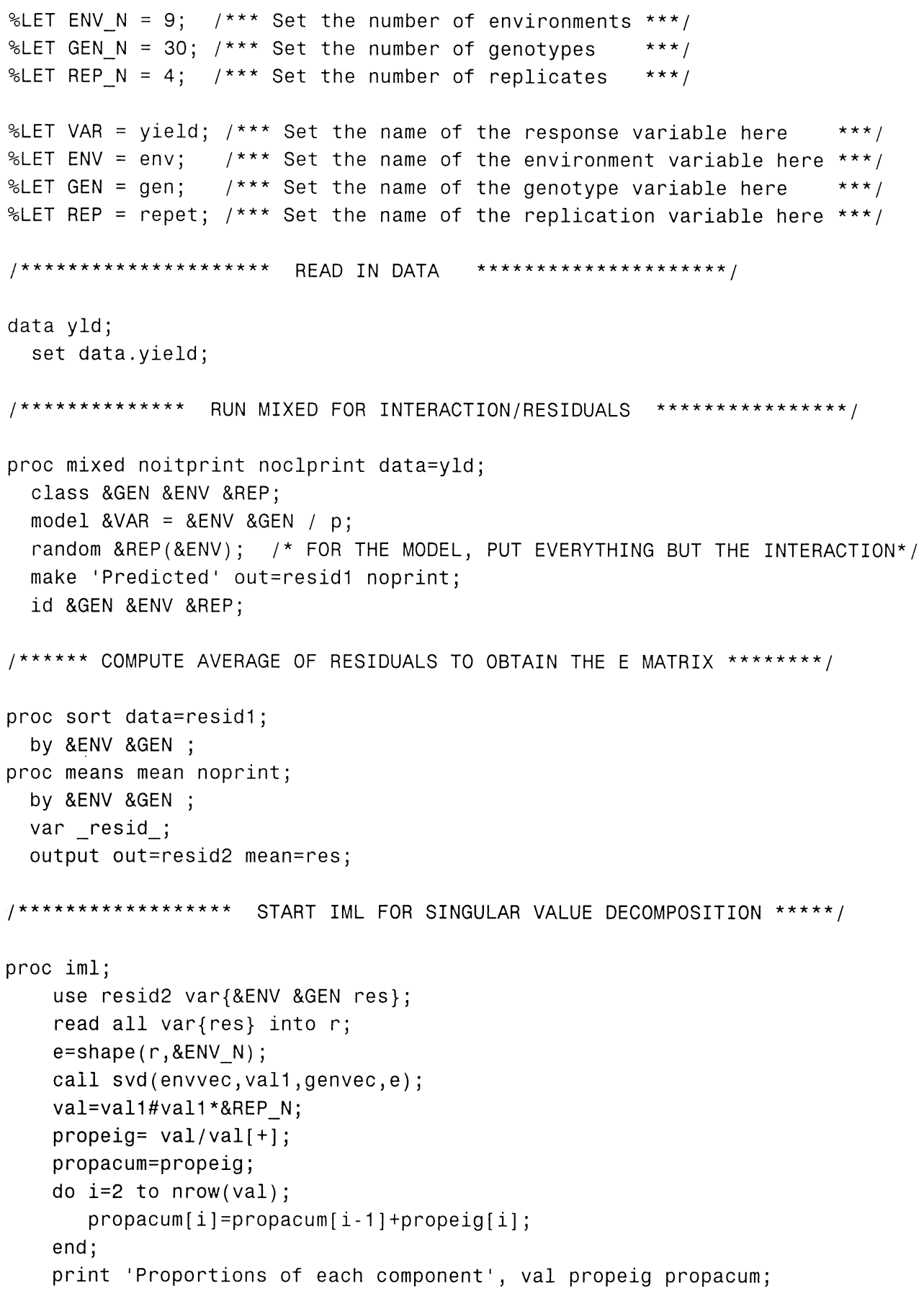




\section{Applied Statistics in Agriculture}

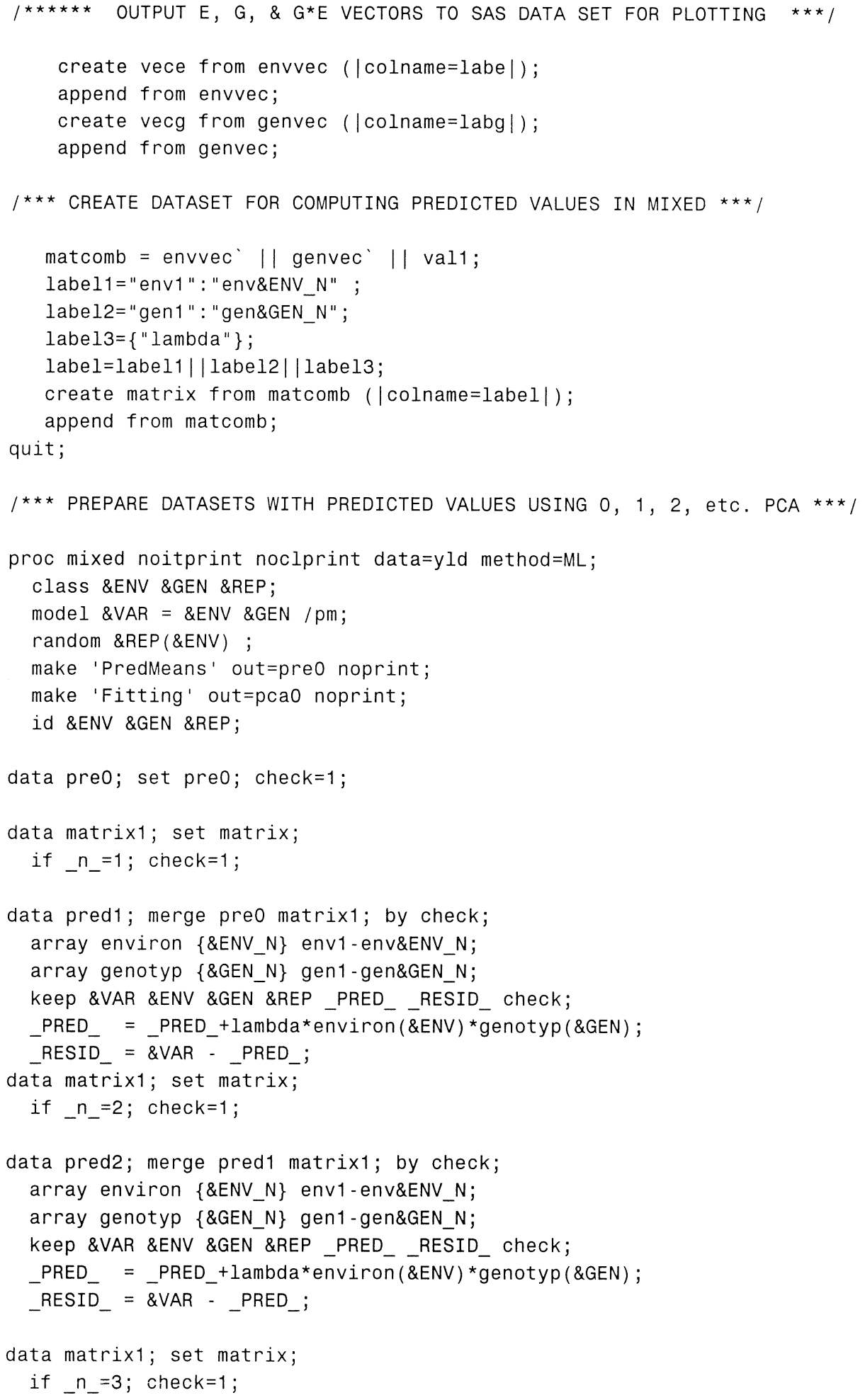




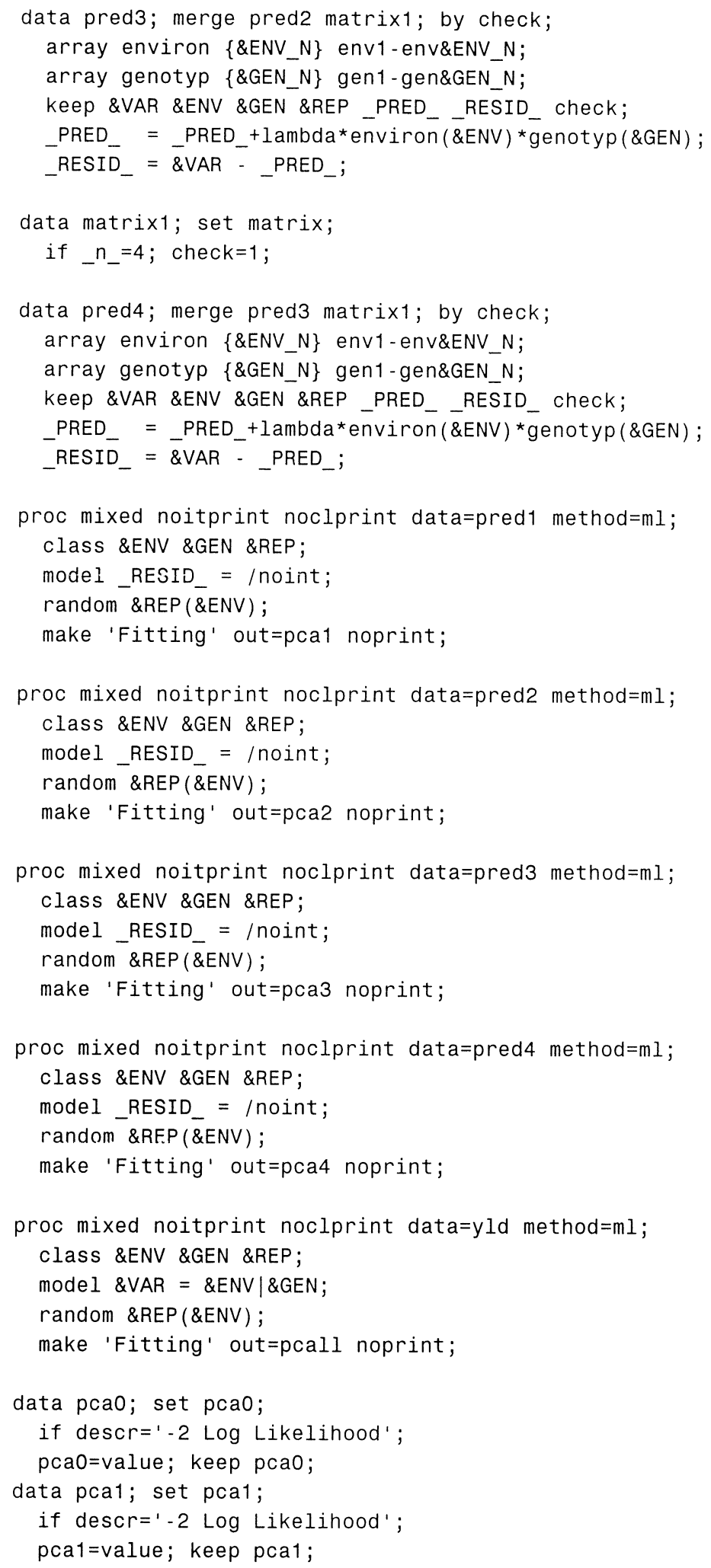




\section{Applied Statistics in Agriculture}

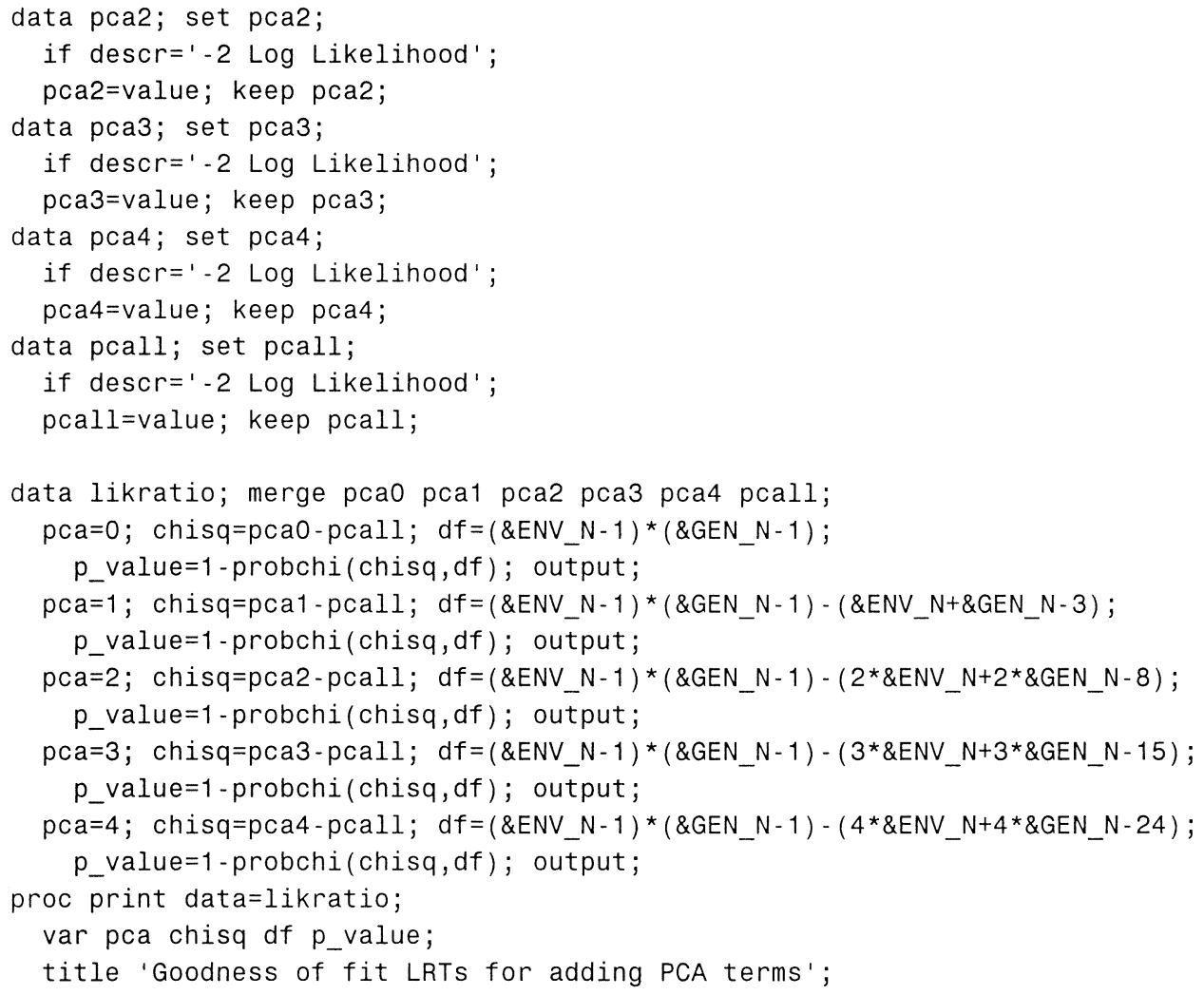

